\title{
Comparison of Forecasting Volatility in the Czech Republic Stock Market
}

\author{
Eleftherios I. Thalassinos ${ }^{1}$, Erginbay Ugurlu ${ }^{2} \&$ Yusuf Muratoglu ${ }^{3}$ \\ ${ }^{1}$ Professor, University of Piraeus, Department of Maritime Studies, Greece \\ ${ }^{2}$ Assistant Professor, Hitit University FEAS, Department of Economics, Turkey \\ ${ }^{3}$ Research Assistant, Gazi University FEAS, Department of Economics, Turkey \\ Correspondence: Eleftherios I. Thalassinos, University of Piraeus, Department of Maritime Studies, Greece.
}

Received: September 22, 2014

Accepted: October 13, $2014 \quad$ Available online: December 11, 2014

doi:10.11114/aef.v2i1.608

URL: http://dx.doi.org/10.11114/aef.v2i1.608

\begin{abstract}
The aim of this paper is to examine different GARCH models with three different distributions in order to compare their forecasting power in terms of volatility existing in the returns of the Czech Stock Market and more specific in the PX index, for the period 08.01.2001-20.07.2012. We have employed GARCH, GJR-GARCH and EGARCH models against normal, student-t and generalized error distributions. Then, we have forecasted stock market volatility for the Czech Republic by its returns using the same models, GARCH, GJR-GARCH and EGARCH comparing their forecasting performance. The results show that return volatility can be characterized by significant persistence and asymmetric effects. We have estimated the corresponding variances for all models for the full sample period using static forecasts. After comparing the forecasting performance of all nine models it was found that the EGARCH model has the best forecasting performance compared to others.
\end{abstract}

Keywords: GARCH models, stock market volatility, forecasting performance

JEL classification: G15, G17

\section{Introduction}

Most financial data have some features which are leptokurtosis, volatility clustering or pooling and leverage effects. Linear structural models and time series models are unable to explain some of the above important features.

Leptokurtosis, volatility clustering or pooling and leverage effects are tendencies for financial asset returns. The tendencies of these features are defined as: a) to have distributions that exhibit fat tails and excess peakedness at the mean; b) to have volatility in financial markets to appear in bunches which means large returns, of either sign and/or small returns, of either sign; c) to have volatility to rise more following a large price fall than following a price rise of the same magnitude (Brooks, 2008).

The most popular non-linear financial models are the Autoregressive Conditional Heteroscedastic (ARCH) or Generalized Autoregressive Conditional Heteroscedastic (GARCH) which have been used for modeling and forecasting volatility proposed by Engle (1982) and Bollerslev (1986).

The aim of this paper is to forecast stock market volatility for Czech Republic by its returns using GARCH, GJR-GARCH and EGARCH models and compare their forecasting performance. The rest of the paper is organized as follows. The second section is a literature review of related studies using GARCH models and stock market volatility. The third section gives brief information about ARCH/GARCH models while the estimation results are presented in the fourth section. The fifth section summarizes and concludes the paper.

\section{Literature Review}

Andersen, Bollerslev and Lange (1999) stated that the expected future volatility of financial market returns is the main ingredient in assessing asset or portfolio risk and plays a key role in derivative pricing models. Emerson, Hall and Zelweska-Mitura (1997) have investigated the Bulgarian stock market while Scheicher (1999) have examined Polish stock returns. Shields (1997) modeled the returns of the Warsaw and Budapest stock exchanges returns. Scheicher (2001) have characterized Hungary, Poland, and Czech markets as principal emerging stock markets in Europe. The author has estimated a VEC model for each market modeling its volatility with a multivariate GARCH (M-GARCH) structure. The findings show that the investigated countries have limited interaction and their volatility has a regional 
character.

Vošvrda and Žikeš (2004) have studied the behavior of volatility and the distributional properties of the Czech, Hungarian, and Polish stock markets using weekly data for the period 1996-2002. They have used the PX-50 index for Czech Republic and have found statistically significant results for GARCH $(1,1)$ model concluding that the volatility of the returns on PX-50 is very persistent.

Syriopoulos (2007) has investigated the relationships between the emerging stock markets, which are Czech Republic, Hungary, Poland, Slovakia and two developed stock markets, Germany and the USA over the period 1997-2003. Haroutounian and Price (2001) have investigated Czech Republic, Hungary, Poland, and Slovakia using both univariate and multivariate GARCH models, namely GARCH, NGARCH, EGARCH, GJR-GARCH, AGARCH, NAGARCH and VGARCH. The research has two parts which are the univariate models and the multivariate models. Relying on the results of the univariate models, they have concluded that strong GARCH effects are apparent for all four markets with the exception of the Czech Republic, where the coefficient of the lagged squared returns is not significant in three out of seven specifications of conditional volatility.

Hajek (2007) has examined the Efficient Market Hypothesis on the Czech capital market for the period 1995-2005 using monthly, weekly and daily data. In this research, the author has analyzed efficiency and linear dependency of several indices closing values and stock closing prices on the Prague Stock Exchange. He has concluded that both daily stock returns and daily index returns are significantly linearly dependent, so the heteroskedasticity-consistent methodology must be therefore applied to avoid significant biases.

Rockinger and Urga (2000) have investigated two groups of countries, which are the transition economies and the established economies. Transition economies are Czech Republic, Poland, Hungary and Russia while the established economies are USA, Germany and UK. Although they have focused on a sample of Central and Eastern European Financial Markets (CEEFM) ${ }^{1}$ they have only used these four countries. The model results are very similar for the Czech Republic, Hungary and Poland while for all countries investigated significant GARCH effects have been appeared.

Thalassinos and Politis (2011) have analyzed international stock markets for a number of countries using cointegration analysis. They have found interrelationships between the selected variables a result that is consistent with other similar studies.

Thalassinos, Maditinos and Paschalidis (2012) have observed significant evidence regarding insider trading in the Athens Stock Exchange in the period 2000-2011.

\section{Methodology}

We have used four different types of GARCH models, ARCH, GARCH, GJR-GARCH and EGARCH structures as follows:

\subsection{ARCH Model}

$\mathrm{ARCH}$ model is based on the variance of the error term at time $t$ and depends on the realized values of the squared error terms in lagged periods. The model is specified as in equations (1) to (3):

$$
\begin{gathered}
\mathrm{y}_{\mathrm{t}}=\mathrm{u}_{\mathrm{t}} \\
\mathrm{u}_{\mathrm{t}} \sim \mathrm{N}\left(0, \mathrm{~h}_{\mathrm{t}}\right) \\
\mathrm{h}_{\mathrm{t}}=\alpha_{0}+\sum_{\mathrm{t}=1}^{\mathrm{q}} \alpha_{\mathrm{j}} \mathrm{u}_{\mathrm{t}-\mathrm{i}}^{2}
\end{gathered}
$$

This model is referred as $\operatorname{ARCH}(q)$, where q refers to the order of the lagged squared returns included in the model. If we use ARCH(1) model equation (3) becomes:

$$
\mathrm{h}_{\mathrm{t}}=\alpha_{0}+\alpha_{1} \mathrm{u}_{\mathrm{t}-1}^{2}
$$

Since $h_{t}$ is a conditional variance, its value must always be strictly positive; a negative variance at any point in time would be meaningless. To have positive conditional variance estimates, all of the coefficients in the conditional variance are usually required to be non-negative. Thus coefficients must satisfy the condition $\alpha_{1} \geq 0$.

\subsection{GARCH Model}

Bollerslev (1987) and Taylor (1986) developed the GARCH(p, q) model. The model allows the conditional variance of

1 Czech Republic, Poland, Hungary, Russia, Bulgaria, Slovenia, Romania, Croatia and Estonia 
the variable to be dependent upon previous lags; first lag of the squared residual from the mean equation presents news about the volatility from the previous period which is as follows:

$$
\mathrm{h}_{\mathrm{t}}=\alpha_{0}+\sum_{\mathrm{i}=1}^{\mathrm{q}} \alpha_{\mathrm{i}} \mathrm{u}_{\mathrm{t}-\mathrm{i}}^{2}+\sum_{\mathrm{i}=1}^{\mathrm{p}} \beta_{\mathrm{i}} \mathrm{h}_{\mathrm{t}-\mathrm{i}}
$$

In the literature the most used and the simplest model is the $\operatorname{GARCH}(1,1)$ process, for which the conditional variance can be written as in equation (6):

$$
\mathrm{h}_{\mathrm{t}}=\alpha_{0}+\alpha_{1} \mathrm{u}_{\mathrm{t}-1}^{2}+\beta_{1} \mathrm{~h}_{\mathrm{t}-1}
$$

Under the hypothesis of covariance stationarity, the unconditional variance $h_{t}$ can be found by taking the unconditional expectation of equation (6). Thus:

$$
\mathrm{h}=\alpha_{0}+\alpha_{1} \mathrm{~h}+\beta_{1} \mathrm{~h}
$$

Solving equation (6) we have:

$$
\mathrm{h}=\frac{\alpha_{0}}{1-\alpha_{1}-\beta_{1}}
$$

For the existence of this unconditional variance it is required to have $\alpha_{1}+\beta_{1}<1$ and in order to be positive it must be $\alpha_{0}>0$.

\subsection{GJR GARCH Model}

The GJR model is a simple extension of GARCH with an additional term added to account for possible asymmetries (Brooks, 2008). Glosten, Jagannathan and Runkle (1993) developed the GARCH model which allows the conditional variance to have a different response to past negative and positive innovations as shown in equation (9):

$$
\mathrm{h}_{\mathrm{t}}=\alpha_{0}+\sum_{\mathrm{i}=1}^{\mathrm{q}} \alpha_{\mathrm{i}} \mathrm{u}_{\mathrm{t}-\mathrm{i}}^{2}+\gamma_{\mathrm{i}} \mathrm{u}_{\mathrm{t}-\mathrm{i}}^{2} \mathrm{~d}_{\mathrm{t}-1}+\sum_{\mathrm{i}=1}^{\mathrm{p}} \beta_{\mathrm{j}} \mathrm{h}_{\mathrm{t}-\mathrm{j}}
$$

Where $d_{t-1}$ is a dummy variable with values for bad and good news:

$$
\mathrm{d}_{\mathrm{t}-1}= \begin{cases}1 \text { if } \mathrm{u}_{\mathrm{t}-1}<0, & \text { bad news } \\ 0 \text { if } \mathrm{u}_{\mathrm{t}-1} \geq 0, & \text { good news }\end{cases}
$$

In this model, the effect of good news shows their impact by $\alpha$, while bad news shows their impact by $\alpha+\gamma$. In addition if $\gamma \neq 0$ news impact is asymmetric and $\gamma>0$ leverage effect exists. To satisfy non-negativity condition coefficients would be $\alpha_{0}>0, \alpha_{i}>0, \beta \geq 0$ and $\alpha_{i}+\gamma_{i} \geq 0$. That is the model is still acceptable, even if $\gamma_{\mathrm{i}}<0$, provided that $\alpha_{\mathrm{i}}+\gamma_{\mathrm{i}} \geq 0$ (Brooks, 2008).

\subsection{Exponential GARCH MODEL}

Exponential GARCH (EGARCH) proposed by Nelson (1991), has formed leverage effects in the equation. In EGARCH model the specification for the conditional covariance is given by the following equation (10):

$$
\log \left(h_{t}\right)=\alpha_{0}+\sum_{j=1}^{q} \beta_{j} \log \left(h_{t-j}\right)+\sum_{i=1}^{p} \alpha_{i}\left|\frac{u_{t=i}}{\sqrt{h_{t=i}}}\right|+\sum_{k=1}^{r} \gamma_{k} \frac{u_{t-k}}{\sqrt{h_{t-k}}}
$$

The two advantages stated in Brooks (2008) for the pure GARCH specification are: a) by using $\log \left(h_{t}\right)$ even if the parameters are negative the equation will be positive; b) asymmetries are allowed under the EGARCH formulation.

In equation (10), $\gamma_{\mathrm{k}}$ represents leverage effect, which accounts for the asymmetry of the model. While the basic GARCH model requires these restrictions, the EGARCH model allows unrestricted estimation of the variance (Thomas and Mitchell, 2005).

If $\gamma_{\mathrm{k}}<0$, this is an indication that leverage effect exist, where $\gamma_{\mathrm{k}} \neq 0$ indicates an asymmetric impact in the model. The meaning of the existence of leverage effect because of bad news increases the volatility.

When applying GARCH models to return series, it is often found that GARCH residuals still tend to be heavy tailed. To accommodate this, rather than to use normal distribution the Student's $t$ and GED distribution have to be used to employ ARCH/GARCH type models (Mittnik, Paolella and Rachev, 2002, Nelson, 1991). 


\subsection{Empirical Application}

We have used daily data in stock exchanges of Czech Republic PX ${ }^{2}$ for the period 08.01.2001-20.07.2012. Statistical data have been collected from Reuters. We have used the return term which is defined in Yu (2002) as follows:

$$
r=\log \left(\frac{x_{t}}{x_{t-1}}\right)
$$

Where $\mathbf{X}_{\mathbf{t}}$ is the capital index.

Graph 1 shows PX and its returns which is defined as RPX.
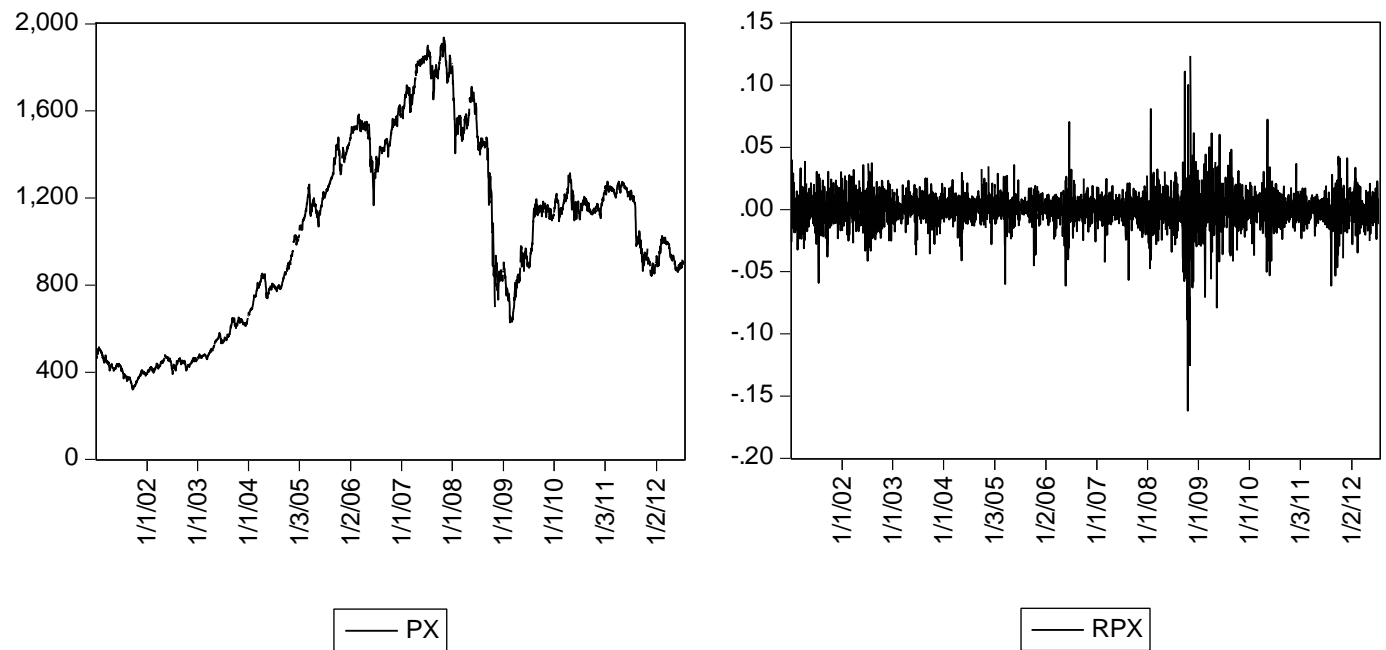

Graph 1. Daily Prices of PX and RPX

Source: Reuters

Table 1 summarizes the descriptive statistics of PX and RPX, which have negative skewness and high positive kurtosis. These values signify that the distributions of the series have a long left tail and leptokurtic form. Jarque-Bera (JB) statistics reject the null hypothesis of normal distribution at $1 \%$ level of significance.

Table 1. Descriptive Statistics

\begin{tabular}{lc}
\hline & RPX \\
\hline Mean & 0.000210 \\
Median & 0.000721 \\
Maximum & 0.123641 \\
Minimum & -0.161855 \\
Std. Dev. & 0.015431 \\
Skewness & -0.524060 \\
Kurtosis & 15.43870 \\
Jarque-Bera & 18821.75 \\
Probability & 0.000000 \\
Sum & 0.609240 \\
Sum Sq. Dev. & 0.690062 \\
Observations & 2899 \\
\hline
\end{tabular}

2 See: http://www.pse.cz/dokument.aspx?k=Exchange-Indices for description of PX 
Table 2. Shows Augmented Dickey-Fuller (ADF) Test Results And Concludes That RPX Is Stationary.

\begin{tabular}{lcccc}
\hline & \multicolumn{2}{c}{ Without Trend } & \multicolumn{2}{c}{ With Trend } \\
\hline Variable & ADF stat & $\mathrm{p}$ & ADF stat & $\mathrm{p}$ \\
RPX & $-39.7972 * * *$ & 0.0000 & $-39.8306 * * *$ & 0.0000 \\
Note: $* * *$ denotes significant at $1 \%$ level. & & & \\
\hline
\end{tabular}

We have also tested the mean model for an ARCH effect with the ARCH-LM Test. Table 3 shows ARCH-LM test results. If the value of the test statistic is greater than the critical value from the distribution, the null hypothesis is rejected indicating that there is no $\mathrm{ARCH}$ effect in the model.

Table 3. ARCH (1) LM Test Results

\begin{tabular}{|c|c|c|}
\hline Dependent Variable of Model & ARCH(1)LM Stat & $\mathrm{P}$ \\
\hline RPX & $429,7907 * * *$ & 0.0000 \\
\hline
\end{tabular}

Note: *** denotes significant at $1 \%$ level.

We have employed ARCH, GARCH, GJR-GARCH and EGARCH processes using both Student-t and Generalized Error distributions in addition to Normal distribution. Results show that strong GARCH and GJR-GARCH effects are apparent for returns (Table 5, Table 6 and Table 7). The sum of the coefficients $\alpha$ and $\beta$ are less than 1 for all different distributions using GARCH and GJR-GARCH models. Nevertheless, the estimation of $\alpha$ is smaller than the estimation of $\beta$ in both cases, which reveals that negative shocks haven't a larger effect on conditional volatility than the positive shocks of the same magnitude. In GJR-GARCH model $\gamma>0$, which means that the news impact is asymmetric or in other words, bad news increase volatility. In the E-GARCH model negative and significant leverage effect parameter indicates the existence of the leverage effect in returns. In EGARCH model, if GED parameter(r) value is 2 reveals a normal distribution or a leptokurtic distribution if it is less than 2 . In all models $r$ is less than 2 and statistically significant, which indicates that RPX is leptokurtic. This result is consistent with the skewness values reported in Table 1 .

After all, ARCH effect is tested in all models. The null hypothesis that there is no ARCH effect cannot be rejected in all models as shown in Table 5, 6 and 7. In the case of GJR-GARCH model with normal distribution, the null hypothesis is rejected at $10 \%$ level of significance.

The in-sample evidence provides the history performance of the models. We have estimated variance for all models for full sample period using static forecast. Then, we compared the forecasting performance of models which have been used in this research. We have considered four statistics for evaluating the forecasting accuracy, which are employed in the research of Wang and Wu (2012). These four measures are the Mean Square Error (MSE) and the Mean Absolute Error (MAE) shown in equations (12) to (15):

$$
\begin{aligned}
& \operatorname{MSE}_{1}=n^{-1} \sum_{t-1}^{n}\left(\sigma_{t}^{2}-\hat{\sigma}_{t}^{2}\right)^{2} \\
& \operatorname{MSE}_{1}=n^{-1} \sum_{t-1}^{n}\left(\sigma_{t}-\hat{\sigma}_{t}\right)^{2} \\
& \operatorname{MAE}_{1}=n^{-1} \sum_{t-1}^{n}\left|\sigma_{t}^{2}-\hat{\sigma}_{t}^{2}\right| \\
& \operatorname{MAE}_{2}=n^{-1} \sum_{t-1}^{n}\left|\sigma_{t}-\hat{\sigma}_{t}\right|
\end{aligned}
$$

Where:

$\mathrm{n}$ is the number of forecasts

$\sigma_{t}^{2}$ is the actual volatility 
$\hat{\sigma}_{t}^{2}$ is the volatility forecast at day t.

Table 4 shows the forecasting performance of GARCH, GJR-GARCH and EGARCH models. Generally, we have found that EGARCH model has the greatest forecasting accuracy according to MSE2, MAE1 and MAE2, with only MSE1 showing better performance for GJR-GARCH.

Table 4. Comparison Forecasting Performance of GARCH Models

\begin{tabular}{lcccccccccc}
\hline & \multicolumn{3}{c}{ Normal Distribution } & \multicolumn{3}{c}{ Student $\mathrm{t}$ Distribution } & \multicolumn{4}{c}{ GED } \\
& GARCH & GJR-GARCH & EGARCH & GARCH & GJR-GARCH & EGARCH & GARCH & GJR-GARCH & EGARCH \\
\hline MSE1 & $6.30 \mathrm{E}-07$ & $6.05 \mathrm{E}-07$ & $6.25 \mathrm{E}-07$ & $6.31 \mathrm{E}-07$ & $6.08 \mathrm{E}-07$ & $6.29 \mathrm{E}-07$ & $6.31 \mathrm{E}-07$ & $6.06 \mathrm{E}-07$ & $6.27 \mathrm{E}-07$ \\
MSE2 & 0.000480 & 0.000478 & 0.000460 & 0.000478 & 0.000477 & 0.000459 & 0.000478 & 0.000476 & 0.000459 \\
MAE1 & 0.000243 & 0.000239 & 0.000234 & 0.000242 & 0.000239 & 0.000234 & 0.000242 & 0.000239 & 0.000234 \\
MAE2 & 0.015476 & 0.015387 & 0.015342 & 0.015447 & 0.015398 & 0.015321 & 0.015439 & 0.015387 & 0.015315
\end{tabular}

Note: The values in bold face refer to smallest loss.

\section{Conclusion}

The article has examined three GARCH models namely GARCH, GJR-GARCH and EGARCH using three different distributions, the Normal distribution, Student-t and Generalized Error distribution, in order to compare their forecasting power for the volatility of the returns of the PX index for the Czech Republic stock market.

The results have shown that significant ARCH and GARCH effects are present in the data, which indicates that the volatility in PX index returns are characterized by significant persistence and asymmetric effects. These results are consistent with the results of Rockinger and Urga (2000), Haroutounian and Price (2010) and Vošvrda and Žikeš (2004) which have used similar GARCH type models for the Czech stock market.

Finally, we have compared the in sample forecasting performance of the nine models for the period 08.01.2001-20.07.2012. The evidence shows that EGARCH model has the best forecasting performance based on real statistical data.

\section{References}

Andersen, T. G., Bollerslev, T., \& Lange, S. (1999). Forecasting Financial Market Volatility: Sample Frequency vis-a-vis Forecast Horizon, Journal of Empirical Finance, 6(5), 457-477.

Bollerslev, T. (1986). Generalized Autoregressive Conditional Heteroskedasticity, Journal of Econometrics, 31(3), 307-327.

Bollerslev, T. (1987). A Conditional Heteroskedastic Time Series Model for Speculative Prices and Rates of Return, Review of Economics and Statistics, 69(3), 542-547.

Brooks, C. (2008). Introductory Econometrics For Finance: Second Edition, Cambridge University Pres.

Emerson, R., Hall, S., \& Zelweska-Mitura, A. (1997). Evolving Market Efficiency with an Application to Some Bulgarian Shares, Economics of Planning, 30(2-3), 75-90.

Engle, R. F. (1982). Autoregressive Conditional Heteroskedasticity With Estimates of the Variance of UK İnflation, Econometrica , 50(4), 987-1008.

Glosten, L. R., Jagannathan, R., \& Runkle, D. (1993). On the Relation Between the Expected Values and the Volatility of the Nominal Excess Return on Stocks, Journal of Finance, 48(5), 1779-1801.

Hájek, J. (2007). Czech Capital Market Weak-Form Efficiency, Selected Issues, Prague Economic Papers, 4, 303-318.

Haroutounian, M. K., \& Price, S. (2001). Volatility İn The Transition Markets of Central Europe, Applied Financial Economics, 11, 93-105.

Mittnik, S., Paolella, M. S., \& Rachev, S. T. (2002). Stationarity of Stable Power-GARCH Processes, Journal of Econometrics, 106, 97-107.

Nelson, D. B. (1991). Conditional Heteroscedasticity in Asset Returns: A New Approach, Econometrica, 59(2), 347-370.

Rockinger, M., Urga, G. (2000). Time Varying Parameters Model to Test for Predictability and Integration in Stock Markets of Transition Economies, CERP Discussion Papers 2346. 
Scheicher, M. (1999). Modeling Polish Stock Returns. in Helmenstein, C. (ed.), Capital Markets in Transition Economies. Cheltenham, Edward Edgar, UK, 417-437.

Scheicher, M. (2001). The Comovements of Stock Markets in Hungary, Poland and the Czech Republic. International Journal of Finance and Economics, 6, 27-39.

Shields, K. (1997). Stock Return Volatility on Emerging Eastern European Markets. The Manchester School Supplement, $118-138$

Syriopoulos, T. (2007). Dynamic Linkages Between Emerging European And Developed Stock Markets: Has The Emu Any Impact, International Review of Financial Analysis 16, 41-60.

Taylor, S. J. (1986). Modelling Financial Time Series, John Wiley \& Sons, Chichester.

Thalassinos, I. E., \& Politis, D. E., (2011). International Stock Markets: A Cointegration Analysis, European Research Studies Journal, XII (2), 113-130.

Thalassinos, I. E., Maditinos, D., \& Paschalidis, A. (2012). Observing Evidence of Insider Trading in the Athens Stock Exchange (ASE), Journal of Economic Structures, 1(8), Dec.

Thomas, S. \& Mitchell, H. (2005). GARCH Modeling of High-Frequency Volatility in Australia's National Electricity Market, Discussion Paper, Melbourne Centre for Financial Studies.

Vošvrda, M., \& Žikeš, F. (2004). An Application of the GARCH-t Model on Central European Stock Returns, Prague Economic Papers, 1, 26-39.

Wang, Y., \& Wu, C. (2012). Forecasting Energy Market Volatility Using GARCH Models: Can Multivariate Models Beat Univariate Models, Energy Economics.

Yu, J. (2002). Forecasting Volatility in the New Zeal\& Stock Market, Applied Financial Economics, 12, 193-202.

\section{Appendix}

Table 5. Normal Distribution

\begin{tabular}{lccccccc}
\hline & \multicolumn{2}{c}{ GARCH(1,1) } & \multicolumn{2}{c}{ GJR-GARCH } & \multicolumn{2}{c}{ E GARCH } \\
& \multicolumn{2}{c}{ Value } & $\mathrm{p}$ & Value & $\mathrm{p}$ & Value & $\mathrm{p}$ \\
\hline Mean equation & & & & & & & \\
$\alpha_{0}$ & 0.0009 & 0.0000 & 0.0006 & 0.0023 & 0.0005 & 0.0055 \\
Variation equation & & & & & & \\
$\alpha_{0}$ & $4.69 \mathrm{E}-06$ & 0.0000 & $6.07 \mathrm{E}-06$ & 0.0000 & -0.5147 & 0.0000 \\
$\alpha$ & 0.1318 & 0.0000 & 0.0727 & 0.0000 & 0.2531 & 0.0000 \\
$\gamma$ & - & - & 0.1036 & 0.0000 & -0.0687 & 0.0000 \\
$\beta$ & 0.8496 & 0.0000 & 0.8441 & 0.0000 & 0.9636 & 0.0000 \\
AIC & -5.9192 & -5.9291 & -5.9282 \\
SIC & -5.9110 & -5.9188 & & -5.9179 \\
DW-stat & 1.8863 & 1.8888 & & 1.8890 \\
ARCH-LM (1) Test p-value of Chi Sq & 0.306626 & 0.0846 & & 0.1493 \\
Obs. & \multicolumn{7}{c}{2899} \\
\hline
\end{tabular}


Table 6. Student's T Distribution

\begin{tabular}{|c|c|c|c|c|c|c|}
\hline & \multicolumn{2}{|c|}{$\operatorname{GARCH}(1,1)$} & \multicolumn{2}{|c|}{ GJR-GARCH } & \multicolumn{2}{|c|}{ E GARCH } \\
\hline & Value & $\mathrm{p}$ & Value & $\mathrm{p}$ & Value & $\mathrm{p}$ \\
\hline \multicolumn{7}{|l|}{ Mean equation } \\
\hline$\alpha_{0}$ & \multirow{2}{*}{\multicolumn{2}{|c|}{$\begin{array}{lll}0.0009 & 0.0000\end{array}$}} & \multirow[t]{2}{*}{0.0008} & \multirow[t]{2}{*}{0.0000} & $0.0008 c$ & .0001 \\
\hline \multicolumn{3}{|l|}{ Variation equation } & & & & \\
\hline$\alpha_{0}$ & $4.34 \mathrm{E}-06$ & 50.0000 & 5.36E-06 & 0.0000 & 0.47000 & .0000 \\
\hline$\alpha$ & 0.1192 & 0.0000 & 0.0696 & 0.0000 & $0.2354 c$ & .0000 \\
\hline$\gamma$ & - & - & 0.0895 & 0.0000 & $-0.613 c$ & .0000 \\
\hline$\beta$ & 0.8617 & 0.0000 & 0.8563 & 0.0000 & 0.9673 & .0000 \\
\hline AIC & \multicolumn{2}{|c|}{-5.9526} & \multicolumn{2}{|c|}{-5.9583} & \multicolumn{2}{|c|}{-5.9577} \\
\hline SIC & \multicolumn{2}{|c|}{-5.9423} & \multicolumn{2}{|c|}{-5.9459} & \multicolumn{2}{|c|}{-5.9453} \\
\hline DW-stat & \multicolumn{2}{|c|}{1.8855} & \multicolumn{2}{|c|}{1.8872} & \multicolumn{2}{|c|}{1.8873} \\
\hline $\begin{array}{l}\text { ARCH-LM(1) Test } \\
\text { p-value of Chi Sq. }\end{array}$ & \multicolumn{2}{|c|}{0.3879} & \multicolumn{2}{|c|}{0.1387} & \multicolumn{2}{|c|}{0.2596} \\
\hline Obs. & \multicolumn{6}{|c|}{2899} \\
\hline
\end{tabular}

Table 7. Generalized Error Distribution(GED)

\begin{tabular}{|c|c|c|c|c|c|c|}
\hline & \multicolumn{2}{|c|}{$\operatorname{GARCH}(1,1)$} & \multicolumn{2}{|c|}{ GJR-GARCH } & \multicolumn{2}{|c|}{ E GARCH } \\
\hline & Value & $\mathrm{p}$ & Value & $\mathrm{p}$ & Value & $\mathrm{p}$ \\
\hline \multicolumn{7}{|l|}{ Mean equation } \\
\hline$\alpha_{0}$ & 0.0009 & 0.0000 & 0.0007 & 0.0001 & 0.0007 & 0.0002 \\
\hline \multicolumn{7}{|l|}{ Variation equation } \\
\hline$\alpha_{0}$ & $4.56 \mathrm{E}-06$ & 0.0000 & 5.72E-06 & 0.0000 & -0.4947 & 0.0000 \\
\hline$\alpha$ & 0.1256 & 0.0000 & 0.0712 & 0.0000 & 0.2446 & 0.0000 \\
\hline$\gamma$ & - & - & 0.0960 & 0.0000 & -0.0646 & 0.0000 \\
\hline$\beta$ & 0.8546 & 0.0000 & 0.8495 & 0.0000 & 0.9653 & 0.0000 \\
\hline $\mathrm{r}$ & 1.5083 & 0.0000 & 1.534154 & 0.0504 & 1.5329 & 0.0498 \\
\hline AIC & \multicolumn{2}{|c|}{-5.9427} & \multicolumn{2}{|c|}{-5.9493} & \multicolumn{2}{|c|}{-5.9484} \\
\hline SIC & \multicolumn{2}{|c|}{-5.9324} & \multicolumn{2}{|c|}{-5.9369} & \multicolumn{2}{|c|}{-5.9360} \\
\hline DW-stat & \multicolumn{2}{|c|}{1.8856} & \multicolumn{2}{|c|}{1.8876} & \multicolumn{2}{|c|}{1.8878} \\
\hline ARCH-LM (1) Test p-value of Chi Sq. & \multicolumn{2}{|c|}{0.2896} & \multicolumn{2}{|c|}{0.074} & \multicolumn{2}{|c|}{0.1979} \\
\hline Obs. & \multicolumn{6}{|c|}{2899} \\
\hline
\end{tabular}

\section{$(\mathrm{cc}) \mathrm{EY}$}

This work is licensed under a Creative Commons Attribution 3.0 License. 